\title{
The Thermal Energy Influence on the Surface Layer of Construction Steels during Laser Beam Cutting
}

\author{
Martin Ovsik, Michal Stanek, Lenka Hylova, Miroslav Manas, Pavel Stoklasek \\ Tomas Bata Uniersity in Zlin. TGM 5555, 76001 Zlin. Czech Republic. E-mail: ovsik@utb.cz, stanek@utb.cz, hy- \\ lova@utb.cz, manas@utb.cz, pstoklasek@utb.cz
}

\begin{abstract}
The presented article deals with the thermal energy influence on various types of construction steels during laser beam cutting. When the material is cut by a laser, the workpiece is subjected to intensive thermal load. Due to this influence, steels hardness is increased and the structure is changed.

The aim of this study is to verify how the thermal energy influences the surface layer of material during laser cutting. The influence was studied on data measured by DSI (depth sensing indentation) micro-hardness method. Each sample was subjected to cross-section from edge to the distance of $20 \mathbf{~ m m}$ from the edge measurement. To evaluate surface layers during laser cutting, three types of steels with different carbon content 1.0038 (S235JR), 1.1203 (C55) a 1.7131 (16MnCr5) were chosen. The main objective was to determine the distance from the cutting point to the material when cutting with a laser beam, how its micro-mechanical properties and structure change or the distance from the cutting point to the component's hardening.
\end{abstract}

Keywords: Laser beam, thermal influence, steels, indentation hardness, indentation modulus

\section{Introduction}

During the trimming of the material into its final shape, the changes of mechanical properties occur because of the high tensile strength. And the conventional stamping process could be uneconomical. The industrial demand and also advanced evolution in processing technology created a laser cutting as an alternative in trimming. Laser cutting is a well-established industrial process with which it is possible to cut polymeric materials, steels and also nickel super alloys. It is desirable to optimize the cut edge quality and cutting speeds. Noncontact cutting with the high quality and cost effectiveness made laser cutting as a process commonly used in the industry $[1,2]$.

During laser cutting of metals, a volume of the melt is created and subsequently blown out of the cut zone by an inert assist gas and a thin layer of the melt flows down the cut. This issue J. Pocorni, J.Powell, E. Deichsel, J. Frostevarg, A.F.H. Kaplan investigated. In case of $10 \mathrm{~mm}$ stainless steel AISI 304 (EN 1.4301) cut by fibre laser has been found in the cut front an average speed $0.4 \mathrm{~m} / \mathrm{s}$ the humps move down the cut, while the liquid flows at the speed of $1.1 \mathrm{~m} / \mathrm{s}$. Their study developed a new experimental technique which allowed high speed imaging observation under standard cutting conditions. The decrease in cut edge quality during processing of thicker section of steel could be a consequence of hump generation [1].

A.F.M. Tahir and S.N. Aqida used as a material 22MnB5 boron steel of $1.7 \mathrm{~mm}$ thickness for laser cutting. Conducting laser cutting at $100 \%$ duty cycle produced the narrowest top kerf of $0.2920 \mathrm{~mm}$, middle kerf of $0.2782 \mathrm{~mm}$ and bottom kerf of 0.2448 and a minimum heat affected zone of $0.1589 \mathrm{~mm}$. The minimum kerf and heat affected zone formation were predicted at $895 \mathrm{~W}$ laser power and $1923.44 \mathrm{~mm} / \mathrm{min}$ cutting speed. These showed the importance of the relationship between input parameters and heat affected zone regions and kerf width formation in laser cutting of these kind of steels [2].

Dorin Catana investigated the heat treatment with concentrated energy sources on nodular cast iron and on grey cast iron. It was found that applying the hardening with these energy sources either cathode beam or laser beam, the improvement of micro-hardness, hardness and wear resistance is obtained [3].

The influence of heat treatments with concentrated energy sources on the alloy steels investigated the same author Dorin Catana and this author studied the alloyed steels X210Cr10 and HS 18-0-1. This author's results show that this treatment leads to the improvement of the properties of the microstructure, hardness and wear resistance [4].

Other studies are concentrated on laser cutting by fibre laser and $\mathrm{CO} 2$ laser of metal materials and comparison of materials with each other, the influence of laser cutting conditions and the thickness of cut materials [5, $6]$.

This article deals with the changes in the material during laser cutting. We are concentrated especially on micro-indentation properties, which are able to describe a huge amount of material properties.

\section{Experimental}

Three types of steels with the different carbon content EN 1.0038 (S235JR), EN 1.1203 (C55), EN 1.7131 $(16 \mathrm{MnCr} 5)$, which are commonly produced and industrially processed were used.

Table 1 shows the chemical composition of the test materials according to the standard ČSN EN 100252:2005. 
Tab. 1 Chemical composition of tested materials.

\begin{tabular}{cccccccccc}
\hline & C max. & Mn max. & Si max. & P max. & S max. & N max. & Cr max. & Mo max. Ni max. \\
\hline $\mathbf{1 . 0 0 3 8}$ & 0.170 & 1.400 & - & 0.045 & 0.045 & 0.009 & - & - & - \\
$\mathbf{1 . 1 2 0 3}$ & 0.600 & 0.900 & 0.400 & 0.030 & 0.400 & - & 0.400 & 0.100 & 0.400 \\
$\mathbf{1 . 7 1 3 1}$ & 0.190 & 1.400 & 0.370 & 0.035 & 0.035 & - & 1.100 & - & - \\
\hline
\end{tabular}

\section{- Laser:}

Tested samples were prepared using a laser of TRUMPF type in the company TAJMAC-ZPS a.s., Zlin. This 2Dlaser cutting machine works on the principle of „flying optics", what means that moving laser cutting head machines the fixed workpiece on the removable machining table. Work dimensions are $1500 \times 3000 \mathrm{~mm}$ and maximum pieces of the material to machine are $20 \mathrm{~mm}$ (construction steel), $15 \mathrm{~mm}$ (stainless steel) and $10 \mathrm{~mm}$ (aluminium) thick. The used power for preparation of tested sample was $1475 \mathrm{~W}$. The temperature of cutting process was up to $106^{\circ} \mathrm{C}$. The maximum power of this laser is 5 $\mathrm{kW}$ with the accuracy of $0.1 \mathrm{~mm}$.

\section{- The preparation of tested samples:}
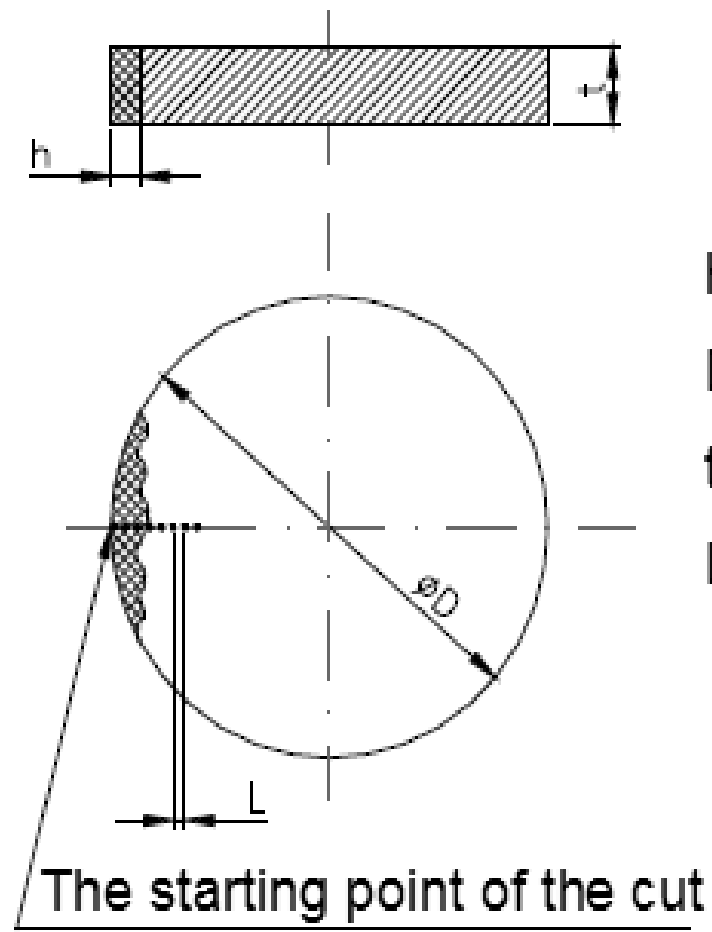

Fig. 1 Tested samples

\section{- Micro-indentation test}

Micro-indentation tests were performed using a microindentation tester (Micro Combi Tester) (Figure 2), made by Anton Paar (Graz, Austria), according to the CSN EN ISO 14577 standard. The tip is made of diamond and its shape is that of a cube corner (Vickers). In the present study, the maximum load used was $1 \mathrm{~N}$, and the loading rate (and unloading rate) was $2 \mathrm{~N} / \mathrm{min}$. The holding time was $90 \mathrm{~s}$. The measurement was carried out using the depth sensing indentation (DSI) method. This method enables one to measure the force acting on the indentor,
Tested samples cut by a laser had to be modified before the micro-hardness measurement. At first, they were cut into the dimensions $(15 \times 15) \mathrm{mm}$ on a precise saw ISOMET 4000 at speed of the cutting disc $1900 \mathrm{rpm}$. Cut tested samples were subsequently moulded into moulding material PHENOCURE on the compression moulding machine SIMPLYMET 1000 at the pressure 290 bar, temperature $150{ }^{\circ} \mathrm{C}$, heating time $1.3 \mathrm{~min}$, cooling time $4 \mathrm{~min}$. The polishing was carried out the polishing machine ECOMET 250 when the moulded prepared tested samples were pushed on various screens at the force $30 \mathrm{~N}$. The screens were alternated according the size of the seed. The speed of the polishing device head was $40 \mathrm{rpm}$. The speed of polishing machine was $100 \mathrm{rpm}$. The final part was carried out the diamond paste CAMEO with the seed size $9 \mu \mathrm{m}$. $h$ - Depth of heat-affected layer

D - Sample diameter

$\mathrm{t}$ - Sample thickness

\section{- Distance between indentations}



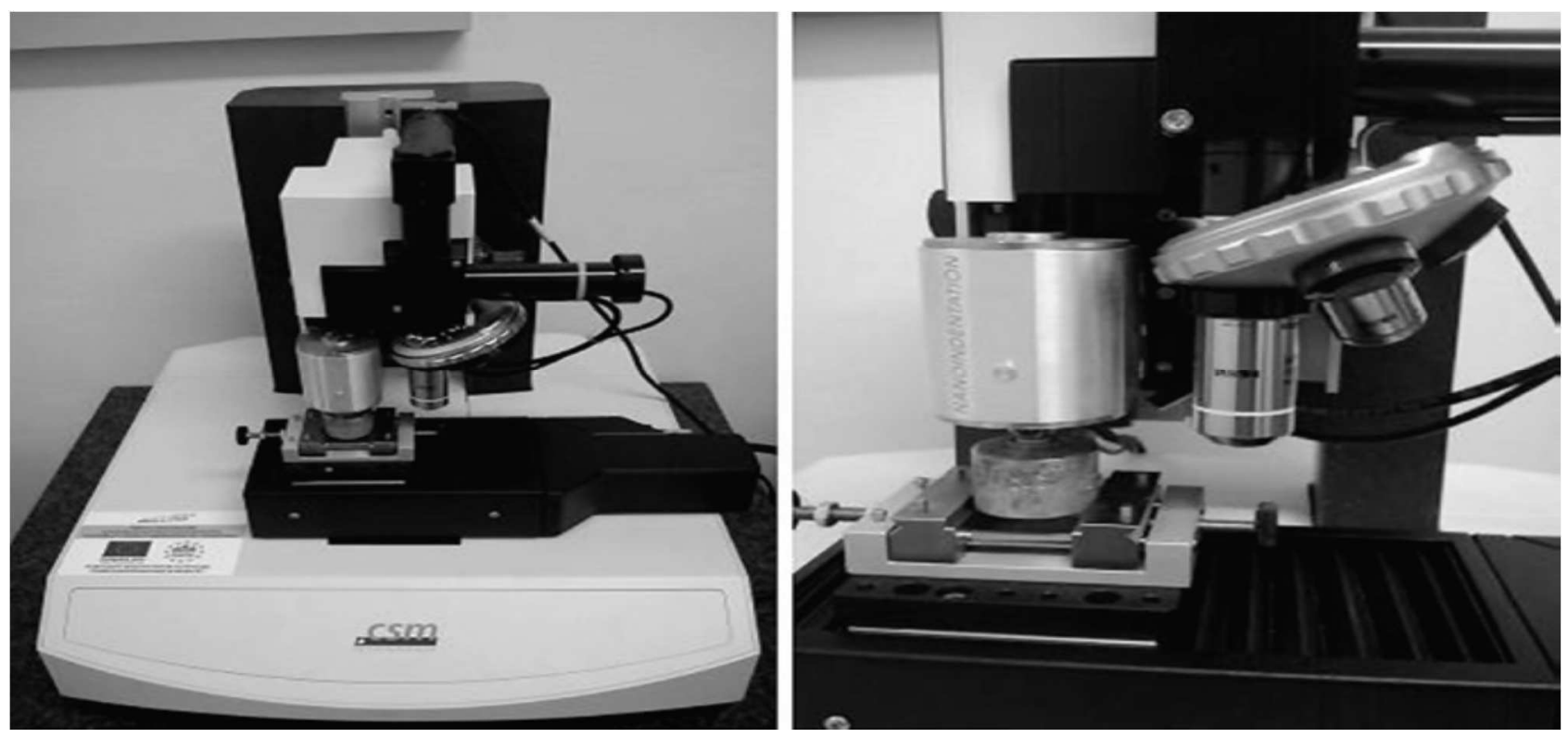

Fig. 2 Micro-indentation tester

\section{Result and Discussion}

The indentation test of hardness was measured from the cut point to the distance of $5000 \mu \mathrm{m}$.

From measured values of the indentation test of hardness of the surface layer at individual types of steels it is evident that the biggest increase of indentation hardness was at the steel 1.1203, at which the value of indentation hardness in the place of the laser cut was $6894 \mathrm{MPa}$.

This value of indentation hardness proves, that the structure of the surface layer was created with martensite and residual austenite (Figure 6). As is evident from Figure 3, the influence of the cut point is approximately 250 $\mu \mathrm{m}$ deep, where the stabilization of indentation hardness on the value $2685 \mathrm{MPa}$ was. The significant increase of hardness was measured at tested steels 1.0038 and 1.7131. At steel 1.7131 indentation hardness in the cut point was $4000 \mathrm{MPa}$ and the influence touched to the distance of $200 \mu \mathrm{m}$. In this area hardness around 2725 $\mathrm{MPa}$ was measured. At the steel 1.0038 the value of indentation hardness in the point of cut was $3471 \mathrm{MPa}$. The measured depth of the influence was at this steel $200 \mu \mathrm{m}$, where the value of hardness was $2195 \mathrm{MPa}$. The structure of both tested materials was created with bainite and residual austenite (Table 1). At all three tested steels with the biggest distance $250 \mu \mathrm{m}$ from the cut point the structure was not significantly influenced by a laser beam and it was created by perlite (the blend of ferite and cementite).

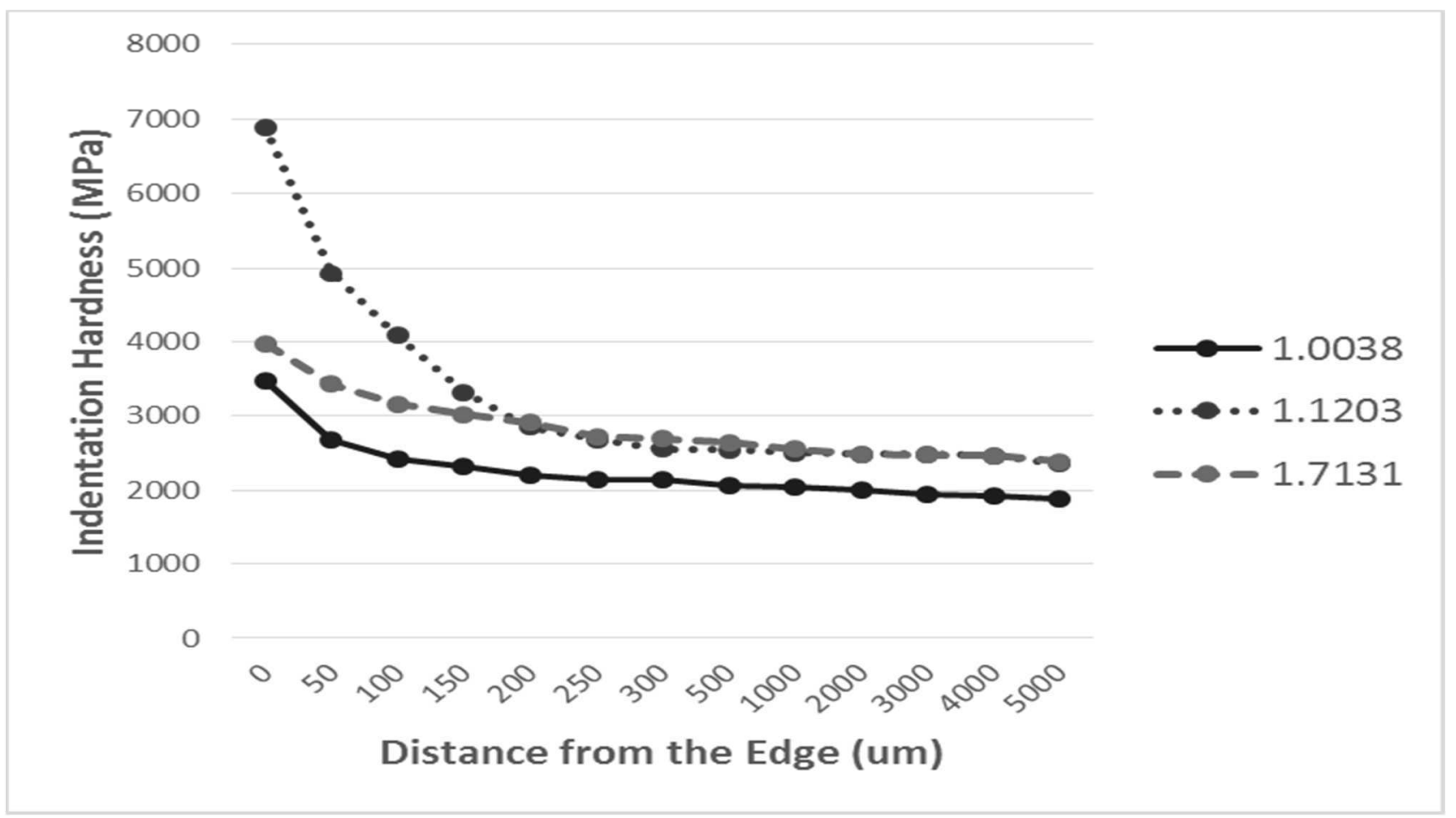

Fig. 3Micro-indentation Hardness 


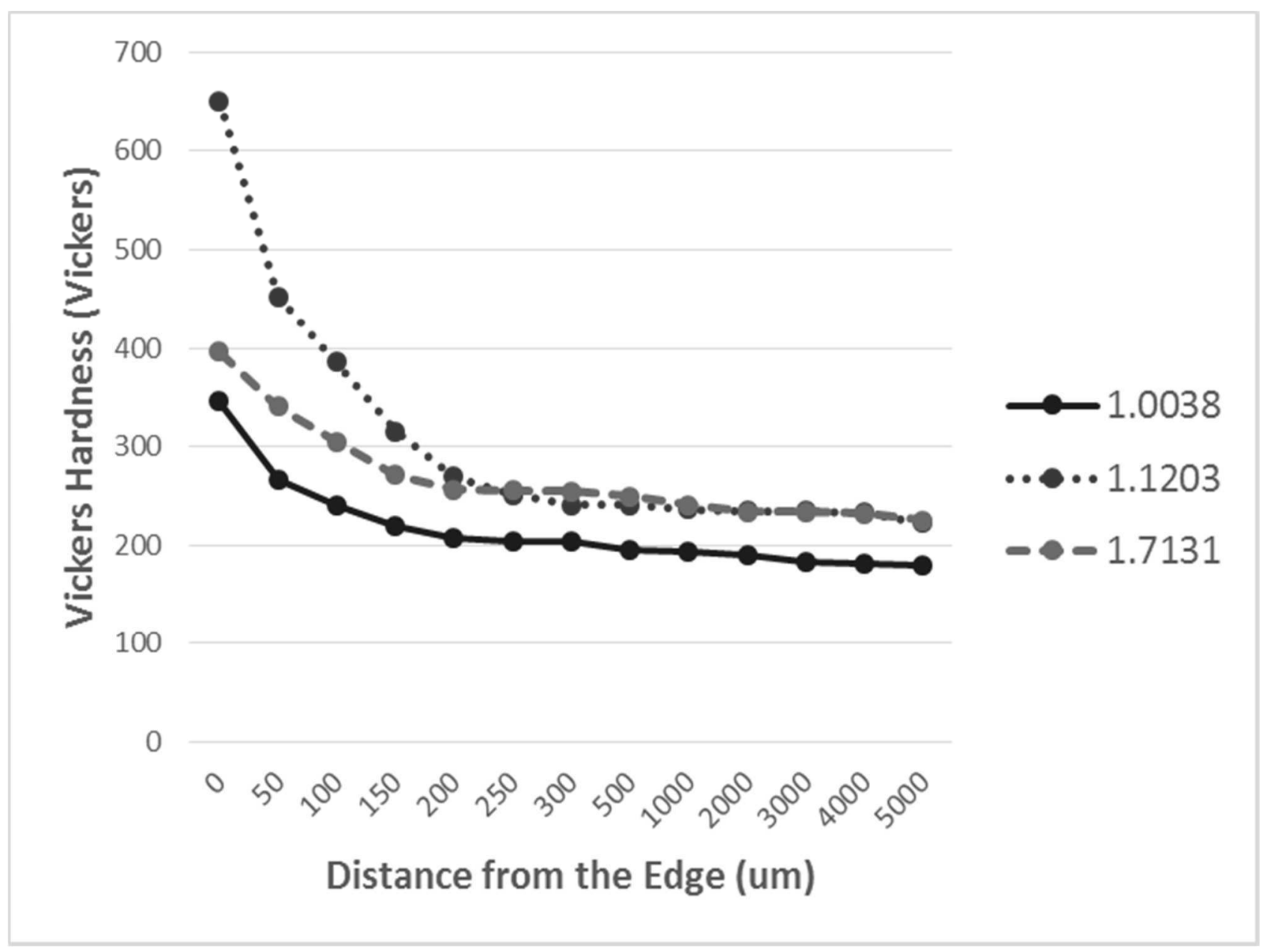

Fig. 4 Vickers Hardness

Tab. 2 Structural Component

\begin{tabular}{|c|c|}
\hline $\begin{array}{l}\text { Phases and structural } \\
\text { components }\end{array}$ & Hardness Vickers \\
\hline Austenite & $120-180$ \\
\hline Rough perlite & $200-250$ \\
\hline Soft perlite & $250-300$ \\
\hline Upper bainite & $300-400$ \\
\hline Lower bainite & $400-550$ \\
\hline Martensite & $600-850$ \\
\hline
\end{tabular}

The micro-hardness measurement of structural components and phases is one of the most important tools for the metallurgy. Using micro-hardness, it is possible to identify and distinguish accurately individual structural components such as upper and lower bainite, low and high carbon martensite etc. Table 1 shows the area of individual hardness of individual structural components and phases in alloys $\mathrm{Fe}-\mathrm{Fe}_{3} \mathrm{C}$.

How is evident from Figure 4, the results of Vickers hardness correspond with the results of indentation hardness. For the steel 1.1203 in the cut point hardness was measured $650 \mathrm{HV}$ what matches the structure created with martensite and residual austenite see Table 2. For the steel 1.7131 in the cut point the value of hardness was 400 $\mathrm{HV}$ and for the steel 1.0038 the hardness in the cut point was measured $346 \mathrm{HV}$. For both materials the hardness value corresponds with the structure of bainite and residual austenite. As is visible from Figure 4, the influence of laser cutting on the surface is $200-250 \mu \mathrm{m}$ deep. From this distance the material is not influenced by the laser temperature and the value of hardness at all three materials moves in the range $200-250 \mathrm{HV}$ what corresponds with the structure of basic material (perlite).

For the tested materials the indentation modulus (Figure 5) was measured, at which the increase in the cut point was recorded. The highest value of indentation modulus was measured in the material 1.1203, in the cut point the value $397 \mathrm{GPa}$ was measured. The non-influenced material showed the value of the indentation modulus $321 \mathrm{GPa}$ and the basic material showed the value 264 GPa. Similar results showed the material 1.0038. The influence was in the depth of $150 \mu \mathrm{m}$. 


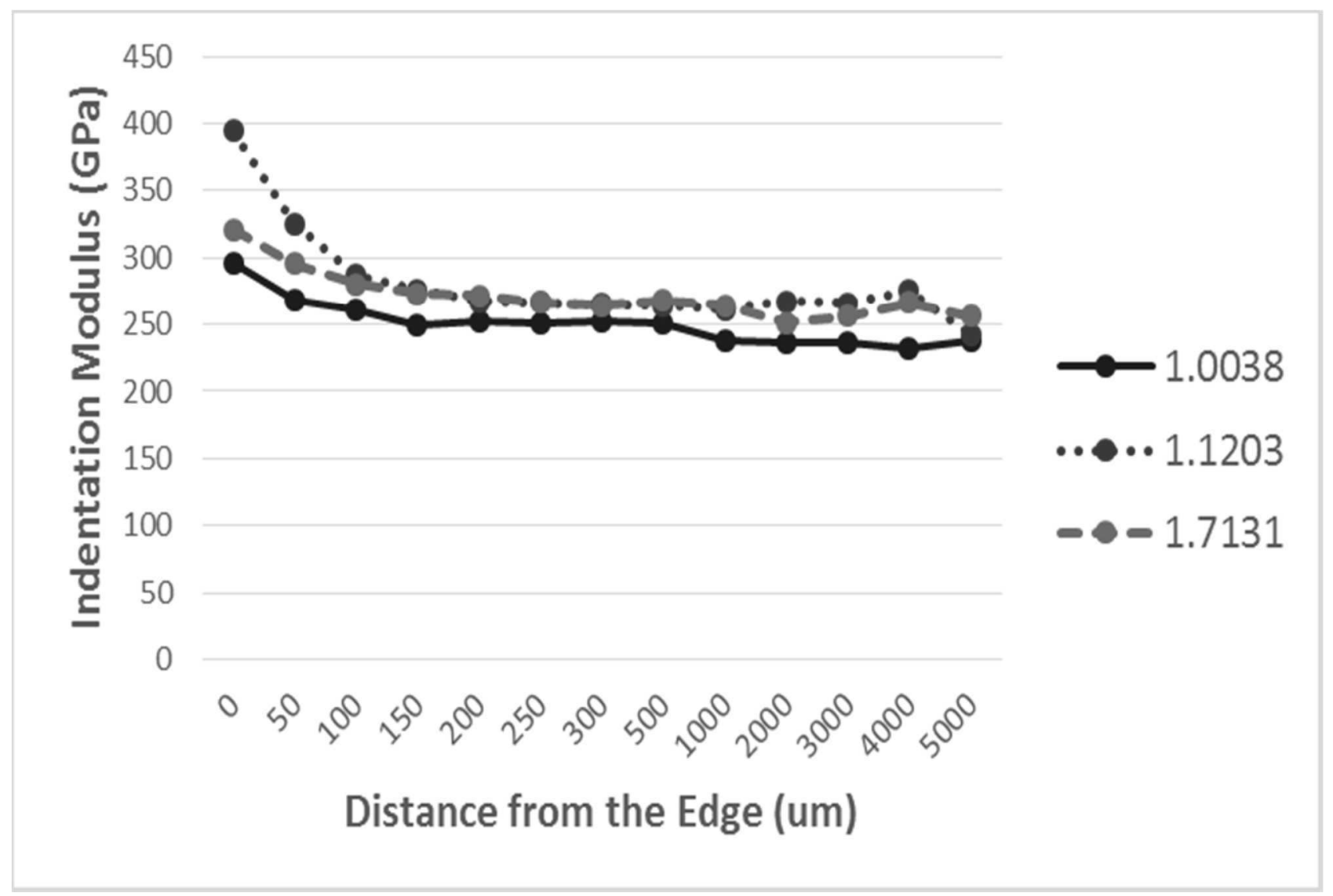

Fig. 5 Micro-indentation Modulus
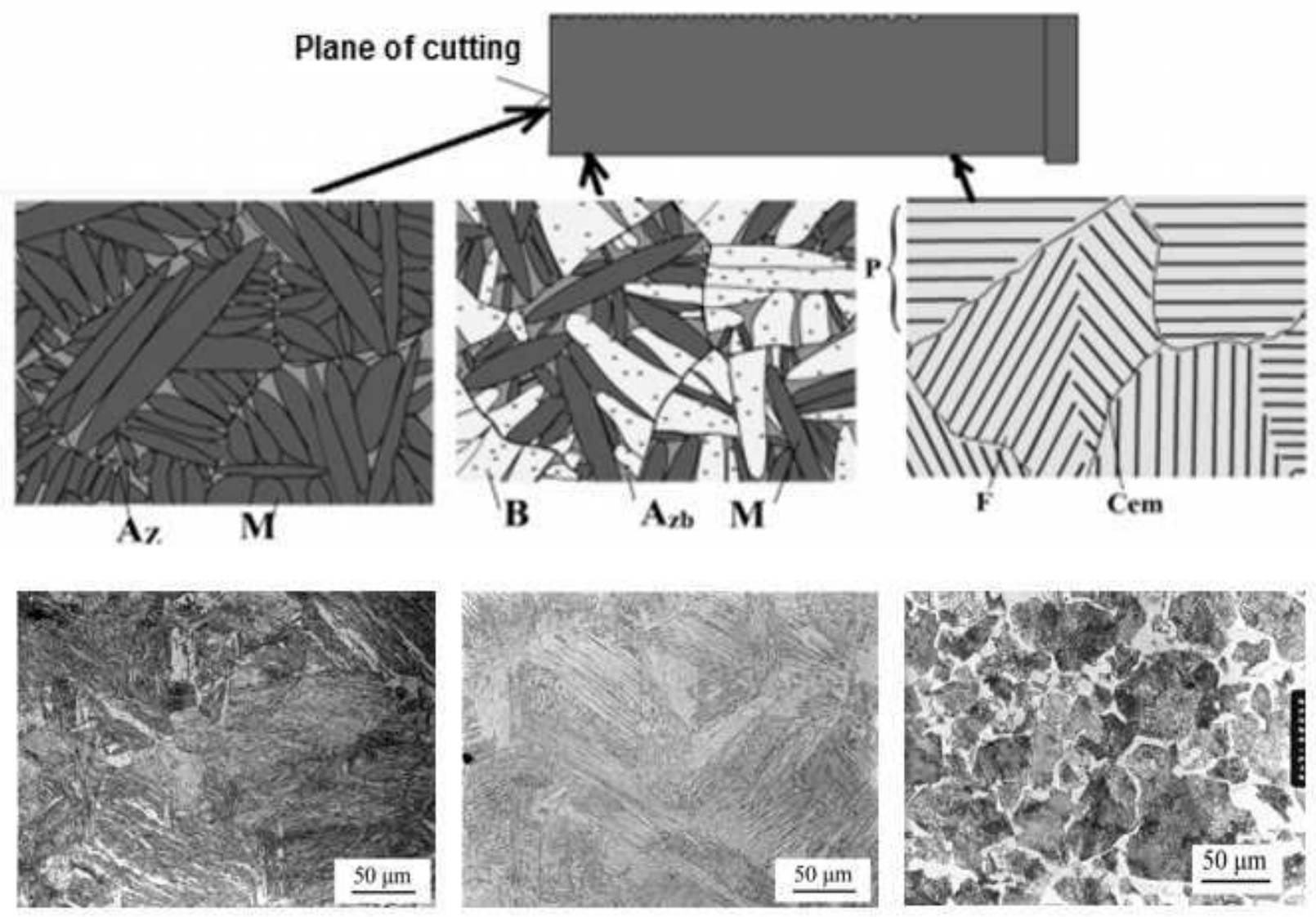

Fig. 6 Structural Component of Teste Samples 


\section{Conclusions}

The presented article deals with the research of the influence of the surface layer of the metal by the laser cutting. Three types of steels with varying carbon content and differing practice usage were chosen.

From the results it is evident that tested samples cut by a laser showed in the proximity of laser cut high hardness. Highest values were measured in the material with higher carbon content 1.1203 (indentation hardness 6894 MPa, Hardness Vickers $650 \mathrm{HV}$ and indentation modulus $397 \mathrm{GPa}$ ). These results correspond to the structure which is created by martensite and residual austenite. Lower values of hardness and modulus in the cut point were measured in the steels with lower carbon content 1.7131 and 1.0038. These results correspond to the structure created by bainite and residual austenite. The maximum depth of the influenced layer was approximately $250 \mu \mathrm{m}$. After this value, hardness was not significantly changed. Micro-mechanical properties corresponded with the basic structure of perlite.

\section{Acknowledgement}

This work was supported by the European Regional Development Fund under the project CEBIA-Tech Instrumentation No. CZ.1.05/2.1.00/19.0376 and by the Ministry of Education, Youth and Sports of the Czech Republic within the National Sustainability Program project no. LO1303 (MSMT-7778/2014). Moreover, it was supported by the Internal Grant Agency of TBU in Zlin: no. IGA/FT/2019/002.

\section{References}

[1] POCORNI, J., POWELL, J., DEICHSEL, E., FROSTEVARG, J., KAPLAN, A.F.H. (2017). Fibre laser cutting stainless steel: Fluid dynamics and cut front morphology. In: Optics and Laser Technology, Vol. 87, pp. 87-93.

[2] TAHIR, A.F.M., AQIDA, S.N. (2017). An investigation of laser cutting quality of $22 \mathrm{MnB5}$ ultra high strength steel using response surface methodology. In: Optics and Laser Technology, Vol. 92, pp. 142-149.

[3] CATATA, D. (2017). Influence of heat treatments with concentrated energy sources on the cast irons mechanical properties. In:Nonconventional Technologies Review, pp. 11-17.

[4] CATANA, D. (2017). Influence of heat treatments with concentrated energy sources on the alloy steels mechanical properties. In: Nonconventional Technologies Review, pp. 22-29.

[5] ORISHICH, A.M., MALIKOV, A.G., SHULYATYEV, V.B., GOLYSHEV, A.A. (2014). Experimental comparison of laser cutting of steel with fiber and $\mathrm{CO} 2$ lasers on the basis of minimal roughness. In:Physics Procedia, Vol. 56, pp. $875-884$.

[6] STELZER, S., MAHRLE, A., WETZIG, A., BEYER, E. (2013).Experimental investigations on fusion cutting stainless steel with fiber and CO2 laser beams. In:Physics Procedia, Vol. 41, pp. 399-404.

[7] OVSIK, M., SENKERIK, V., MANAS, D., STANEK, M. (2016). The behaviour of cross-linking filled PBT measured by nano-hardness. In: MM Science Journal, pp. 1110-1113.

[8] EPERJESI, S., MATVIJA, M., BARTOSOVA, M., FECKO, D., PRIBULOVA, A. (2017). Effect of Heat Treatment Conditions on Micro Structure of Cast Iron. In: Manufacturing Technology, Vol. 17, pp. 29-33.

[9] MULLER, M. (2017). Effects of Aluminium Microparticles and Surface Treatment of AlCu4Mgon Mechanical Properties of Adhesive Bond Strength. In: Manufacturing Technology, Vol. 17, pp. 66-71.

[10] KUBISOVA, M., PATA, V., SYKOROVA, L., KNEDLOVA, J. (2017). Influence of laser beam on polymer materiál. In: Manufacturing Technology, Vol. 17, No. 5, pp. 742-746.

[11] MANAS, D., OVSIK, M., MIZERA, A., MANAS, M., HYLOVA, L., BEDNARIK, M., STANEK, M. (2018). The effect of irradiation on mechanical and thermal properties of selected types of polymers, In: Polymers, Vol. 10, No. 2, pp. 158. 